\title{
EXPLAINING DISAGREEMENT: CONTEXTUALISM, EXPRESSIVISM AND DISAGREEMENT IN ATTITUDE
}

\begin{abstract}
A well-known challenge for contextualists is to account for disagreement. Focusing on moral contextualism, this paper examines recent attempts to address this challenge by using the standard expressivist explanation, i.e., explaining disagreement in terms of disagreement in attitude rather than disagreement in belief. Assuming that the moral disagreements can be explained in terms of disagreement in attitude, this may seem as a simple solution for contextualists. However, it turns out to be easier said than done. This paper examines a number of different ways in which disagreement in attitude can be incorporated into a contextualist framework and argues that each suggestion is problematic. In particular, the purported explanations of disagreement fail to adequately explain intuitive occurrences of disagreement, the robustness of disagreement intuitions and/or locate the disagreement in the intuitively right place.
\end{abstract}

Keywords: contextualism; expressivism; disagreement; disagreement in belief; disagreement in attitude

\section{Introduction}

Contextualism is a view according to which the meaning of certain terms is incomplete and fixed by the context of utterance. ${ }^{1}$ Indexical terms serve as paradigmatic examples. The meaning of "I," "here" or "now," for example, depend on the context (speaker, place and time respectively). A speaker who says "It is hot here" while in Los Angeles picks out a different place than someone who utters the same words in Alaska. Contextualism is also a semantic doctrine that many philosophers find plausible in other domains, e.g., taste, aesthetics and morality. The idea is that terms in these domains, for example, "delicious," "beautiful" and "ought" behave much like indexical terms. However, a well-known problem for contextualism in these domains is its apparent inability to account for intuitive disagreements.

It has recently become rather fashionable to claim that this problem can be avoided by borrowing an idea advanced by Charles Stevenson and standardly associated with expressivism, viz., that disagreement in certain

1 Thanks to Voin Milevski for inviting me to contribute to this issue. I'd also like to thank everyone who at some point or other provided comments on earlier drafts of this paper. This research was funded by Riksbankens Jubileumsfond (RJ) (grant number: P16-0710:1). 
domains should be understood in terms of the parties having conflicting attitudes. This allows for two parties, A and B, to agree in belief about p, yet disagree in virtue of having conflicting attitudes towards $\mathrm{p}$. In this paper, focus is on moral contextualism and moral disagreement. ${ }^{2}$ Given the assumption that moral disagreement is best understood as disagreement in attitude and that the contextualist explanation works, one of the most trenchant objections is thus circumvented. ${ }^{3}$ Moreover, it also undermines the view that intuitive disagreement in the absence of disagreement in belief provides one-sided support for expressivism. This paper examines a number of different ways in which disagreement in attitude can be incorporated into a contextualist framework and argues that each of these ways lead to problems. In particular, the purported explanations of disagreement fail to adequately explain intuitive occurrences of disagreement, the robustness of disagreement intuitions and/ or locate the disagreement in the intuitively right place.

The outline of this paper is as follows. In the next section the standard objection to contextualism is explained. Section 2 introduces the distinction between disagreement in belief and disagreement in attitude and explains how expressivists make use of the latter. Section 3 introduces the basic contextualist maneuver aiming to accommodate disagreement intuitions in terms of disagreement in attitude. In section 4 through 7 I undertake more detailed examinations of contextualist explanations of disagreement in terms of disagreement in attitude but argue that they all fail.

\section{Contextualism and disagreement}

Contextualism is the view that the meaning, reference or truth conditions of a class of sentences depend on features of the context, e.g., place, time or the standard of the judge. For example, the meaning of a sentence involving "here" depends on the place of the speaker. Consider the following short exchange involving John and Jane.

(1) It's hot here.

(2) It's not hot here.

Unless we know that John and Jane are in two different places, we may intuit them as disagreeing (at least assuming that they use the same standard for

2 Although focus is on moral contextualism and moral disagreement, the considerations advanced in this paper will most likely also generalize to contextualism in other domains where contextualism has similar problems with respect to disagreement and where similar solutions are proposed.

3 This paper will simply assume that disagreements in the relevant domains are plausibly thought of as disagreements in attitude (rather than disagreement in belief). Moreover, it also assumes that e.g., approval and disapproval of the same subject are states of mind that disagree. Without such assumptions, appealing to disagreement in attitude would be a non-starter for the contextualist. 
"hotness"). However, if we learn that John is in Los Angeles while Jane is in Alaska, what (1) and (2) really mean is roughly the following.

$\left(1^{\star}\right)$ It's hot in Los Angeles.

$\left(2^{\star}\right)$ It's not hot in Alaska.

Given that (1) and (2) are uttered in two different places, there doesn't seem to be any sense in which John and Jane disagree (as $\left(1^{\star}\right)$ and $\left(2^{\star}\right)$ should make evident). In other words, any sense of conflict should disappear. Moreover, there is nothing odd about this. Consider instead the following example where Mary and Mark ponder whether Huck ought to tell on Jim (the fugitive slave) or not and come to the following conclusions.

(3) Huck ought to tell on Jim.

(4) Huck ought not to tell on Jim.

It seems that Mary and Mark disagree. ${ }^{4}$ Given an invariantist outlook, for example, two beliefs are in conflict if they (or their content) cannot be true simultaneously. However, if contextualism is correct, then it seems that there is no explanation of the conflict. Rather, we arrive at the following rough semantic interpretations.

$\left(3^{*}\right)$ Huck ought to tell on Jim relative to Mary's moral standard.

$\left(4^{\star}\right)$ Huck ought to not tell on Jim relative to Mark's moral standard.

Given these interpretations, there doesn't seem to be any conflict between Mary and Mark's beliefs. For example, it is true that Huck ought to tell on Jim relative to Mary's moral standard and simultaneously true that Huck ought not to tell on Jim relative to Mark's moral standard. Hence, the disagreement is lost. However, by contrast to the indexical example above, the sense of disagreement doesn't go away. Insofar as we ascribe to Mary and Mark the relevant moral beliefs, we seem to think that they disagree, i.e., we intuit that there is a conflict between the parties' respective views. The challenge for contextualists is to find some way of making sense of this. ${ }^{5}$

\section{Disagreement and attitudes}

Issues regarding disagreement play an important role in many areas of philosophy. Famously, moral expressivists have argued that their analyses gain

4 It should be emphasized that "disagreement" is a term that can be used in many different ways. It can be used to say that two parties simply have different views, but the sense relevant here is that their views are somehow in conflict. This is the datum that needs explanation.

5 It should be noted that the idea of making sense of disagreement by using the standard expressivist story also has been suggested in other domains, e.g., taste. Although one may argue that disagreement intuitions regarding matters of taste are less robust or somewhat different, the problems raised in this paper apply generally to such attempts to explain disagreement intuitions. See e.g., Eriksson (2016) for discussion. 
support from the apparent possibility of agreement on all factual matters (or agreement in belief), yet disagreement in moral judgment. ${ }^{6}$ Interestingly, one of the key motivations for some kind of contextualism is also a key part of the expressivist argument from disagreement. One of the premises in the standard expressivist argument is that moral terms like "right," "wrong" or "ought" are subject to systematic variation. For example, we may recognize that Mary and Mark use the terms to systematically pick out different properties. This suggests that the terms have different descriptive meanings in their respective idiolects, but we don't think that this is something that makes either Mary or Mark linguistically confused. ${ }^{7}$ However, if the meaning of moral predicates is context sensitive and different in different peoples' idiolects, then it seems as if it will be difficult to explain the intuitive sense of disagreement. The next move made by expressivists is to argue that apparent disagreement in belief isn't the only sense of disagreement. As Stevenson famously pointed out, we must distinguish between disagreement in belief and disagreement in attitude. A disagreement in belief regarding a certain question occurs in cases where "one man believes that $\mathrm{p}$ is the answer, and another that not-p, or some proposition incompatible with $\mathrm{p}$, is the answer" (Stevenson 1944: 2). For example, if I believe that Paris is in France while you believe that Paris is not in France, you and I disagree in belief. A disagreement in attitude, by contrast, is characterized as follows.

Two men will be said to disagree in attitude when they have opposed attitudes to the same object-one approving of it, for instance, and the other disapproving of it-and when at least one of them has a motive for altering or calling into question the attitude of the other. (Stevenson 1944: 3)

Note that this characterization seems to involve two different conditions, but one may think that the motive for altering or calling into question the attitude of the other isn't strictly speaking necessary. Indeed, in other passages, this condition is omitted. Consider instead the following passage that also addresses the difference between the two senses of disagreement.

The difference between the two senses of "disagreement" is essentially this: the first involves an opposition of beliefs, both of which cannot be true, and the second involves an opposition of attitudes, both of which cannot be satisfied. (Stevenson 1962: 2) ${ }^{8}$

6 This is a prominent argument amongst philosophers in the expressivist tradition. See e.g., Stevenson (1944, 1963), Hare (1952), Gibbard (1990 ch.1), Blackburn (1984: 168, 1991) and Horgan and Timmons (1991). See also Tersman (2006) for a general discussion of moral disagreement. Ayer (1936: 110), by contrast, denies that we disagree about values.

7 Confer Tersman's latitude idea (see Tersman 2006).

8 It is the latter conception that has been the most influential in the development of expressivism (see Ridge 2013: 44). See also Eriksson (2016) for discussion. 
Distinguishing between disagreement in belief and disagreement in attitude opens up conceptual space. Most importantly, it makes it possible to agree in belief, yet disagree in attitude. For example, given that Mary and Mark use "ought" in systematically different ways it seems plausible to think that they will not disagree in belief. It is, in other words, conceivable that they agree on all factual matters. Hence, we need some other way of making sense of the disagreement. Of course, it is at this point that disagreement in attitude becomes important. Although Mary and Mark may agree about all factual matters, it is nevertheless possible that they have opposed attitudes towards telling on Jim. Mary approves of telling on Jim. Mark, by contrast, disapproves of telling on Jim. Consequently, Mary and Mark disagree in attitude. This is what, according to the expressivist, explains the disagreement (i.e., appearance of conflict). Moreover, since a moral disagreement isn't a disagreement in belief, we also have reason to think that moral beliefs aren't beliefs with a mind-to-world direction of fit, but noncognitive states. To believe that one ought to tell on Jim is (roughly) to approve of telling on Jim. To believe that one ought not to tell on Jim is (roughly) to disapprove of telling on Jim.

\section{Contextualism and disagreement in attitude}

Intuitively, Mary and Mark disagree. This is a kind of datum that needs to be explained. The problem for contextualism is that it seems that Mary and Mark aren't really disagreeing since their respective moral views are consistent. However, given that the moral domain also seems to be intimately associated with attitudes and attitudinal expression, perhaps the relevant kind of disagreement is best understood in terms of disagreement in attitude. Although this is an argument that is most intimately associated with expressivism, perhaps contextualists simply can use the same explanation.

The basic idea begins by arguing that the challenge to contextualism rests on a too narrow conception of disagreement. Contextualism, common lore tells us, is unable to account for disagreement. However, this claim has bite only if it is assumed that contextualists must explain disagreement in terms of conflicting propositions or disagreement in belief, but this isn't the only sense of disagreement available. Rather, even if there is no disagreement in belief between Mary and Mark, even if they don't accept inconsistent propositions, there may nevertheless be a disagreement in attitude. ${ }^{9}$ In fact, this is an idea that is widely endorsed. Let me run through some examples.

9 This is not the only way in which one may try to avoid the standard objection to contextualism. For example, one may argue that although the propositions aren't literally inconsistent, there is nevertheless a proposition that is picked out as contextually salient that they disagree about. Consider an example: Suppose that I judge that A has one child. You judge that A has two children. It may be argued that you and I don't express logically 
Supposing that the expressivist manages to account for disagreement in terms of disagreement in attitude, then, as James Dreier, claims "the indexical theorist may say just the same thing that the expressivist says, namely, that there is real disagreement in norms, or in attitude" (Dreier 1999: 569) and "the account of conflict of attitudes can be adopted by Indexical Relativism" (Dreier 2009: 107). Teresa Marques claims that contextualists should not account for disagreement in doxastic terms, but "turn to the incompatibility of non-doxastic attitudes" and that "[t]he existence of non-doxastic disagreement is compatible with a standard form of contextualism" (Marques 2014: 140). Timothy Sundell, similarly, claims that inconsistent propositions are quite irrelevant because "the conflicting attitudes that the speakers express is all that is required to explain their 'taking themselves to disagree"' (Sundell 2011: 282). More generally, but in the same spirit, Frank Jackson and Philip Pettit make the following claim.

Indeed, almost every party to the debate in meta-ethics believes that if I sincerely assert that $\mathrm{X}$ is right and you sincerely assert that $\mathrm{X}$ is wrong, we must have different moral attitudes; so, if that counts as our disagreeing, as expressivists who are not eliminativists about moral disagreement must allow, almost every party to the meta-ethical debate can respond to the problem of moral disagreement simply by noting that a difference in moral attitudes can survive agreement over all the facts. (Jackson and Pettit 1998: 251; see also Jackson 2008)

Other philosophers who have suggested similar ideas include David Wong (1986), Gilbert Harman (1996: 33-37), Gunnar Björnsson and Stephen Finlay (2010), Finlay (2014a, 2014b), Andy Egan (2010), Torfinn Huvenes (2012),

inconsistent propositions because my judgment expresses the proposition that $\mathrm{A}$ has at least one child while you express the proposition that A has at least two children. In this case, both you and I are right, because A has two children. The moral of such examples is that disagreement in talk doesn't require that the speakers are expressing mutually inconsistent propositions (Björnsson and Finlay (2010), Sundell (2011), Plunkett \& Sundell \& (2013), Egan (2014)). This seems right, but also quite trivial. We don't always intuit a disagreement in virtue of the literal proposition expressed, but in virtue of what is intended to be communicated. It may also be argued that the salient standard picked out isn't necessarily the speaker's own, but a group standard of some kind (see e.g., Recanati (2007: ch. 11). The example involving height may also be used to illustrate a different way in which a contextualist may want to maneuver around the problem. What is it that we communicate by disagreeing about the tallness of a certain person? A suggestion is that we disagree "about how to use a certain word appropriately" (Barker 2002: 1-2) (see Plunkett and Sundell (2013) for extended discussion on this matter). Lopez de Sa (2009) argues that "is funny" triggers a presupposition of commonality, i.e., roughly that we are similar with respect to humor. Khoo and Knobe (2016) "locates the disagreement between two speakers in their making incompatible proposals to change some aspect of their conversational context" (Khoo and Knobe 2016: 2). I will not here address these suggestions. Rather, the concern is exclusively with trying to account for disagreements in terms of standard expressivist story, viz., in terms of conflicting attitudes. 
Teresa Marques and Manuel Garcia-Carpintero (2014). This brief summary is probably far from complete, but it shows how widely endorsed the main idea is.

By accounting for disagreement in terms of disagreement in attitude, one of the most trenchant objections to contextualism is dispelled. Moreover, it also undermines the expressivists' claim that disagreement in the absence of disagreement in belief provides one-sided support for expressivism. As Huvenes claims, "thinking about disagreement in this way doesn't force us to adopt a particular semantic theory. One can think about disagreement in this way without endorsing expressivism" (Huvenes 2012: 179). Arguments from disagreement therefore seem to lack semantic significance. However, the idea that contextualism can make sense of disagreement via disagreement in attitude has not been explored in much detail. ${ }^{10}$ Indeed, once one starts examining the idea more closely, it soon becomes clear that it is easier said than done.

\section{Disagreement in expressed attitude}

According to expressivism, moral assertions function to express rather than report attitudes. This is supposed to be something that shows expressivism to be superior to subjectivism because it promises to explain disagreement intuitions. However, there seems to be no good reason to reject the idea that an assertion can function to both report and express an attitude, e.g., if the latter is expressed pragmatically. Björnsson and Finlay (2010), for example, argue that "ought claims relativized to the speaker's own standard will have the conversational role of prescriptions or imperatives" (Björnsson and Finlay 2010: 32; emphasis added). Thus, asserting that Huck ought not to tell on Jim functions to express a proposition (in virtue of its semantics) and a prescription not to tell on Jim (in virtue of the pragmatics). The latter is expressed by virtue of its conversational role. Similarly, Sundell (2011) claims that expressing inconsistent propositions is irrelevant because "the conflicting attitudes that the speakers express is all that is required to explain their 'taking themselves to disagree"' (Sundell 2011: 282). Thus, the basic idea is that two parties disagree because their assertions (in part) function to express conflicting attitudes. ${ }^{11}$ Call this disagreement in expressed attitude:

Disagreement in expressed attitude: A's assertion that $\mathrm{p}$ disagrees with B's assertion that $\mathrm{q}$ in virtue of $\mathrm{A}$ and B's respective assertions expressing conflicting attitudes.

At first glance, this may seem as a plausible way of explaining disagreement intuitions for contextualists. However, there are also some questions that needs to be addressed in order to more fully assess the proposal. One question

10 Köhler (2012) is a notable exception.

11 C.f., Finlay (2014a: 134). 
concerns the expression relation: how does an assertion express an attitude? Björnsson and Finlay seem to think of the expression relation as roughly similar to how conversational implicatures work. Others may think that the expression relation is more a matter of convention. ${ }^{12}$ However, regardless of which option one favors, the proposal runs into problems. First, one can express an attitude that one doesn't have. Second, one can express an attitude that one thinks one has, but be mistaken about this. These possibilities raise questions regarding whether disagreement in expressed attitude actually explains intuitive occurrences of disagreement in the right way.

The problem with disagreement in expressed attitude is, on the one hand, that we risk failing to explain disagreement where they intuitively occur and, on the other hand, that we find disagreement where there intuitively are none. Of course, there will be cases in which we may disagree whether two parties disagree or not. The following two cases, however, are hopefully cases where disagreement intuitions are uniform.

First, suppose that Mark believes that one ought not to tell on Jim and Mary believes that one ought to tell on Jim. Mary, however, is self-deceived and falsely believes that she believes that one ought not to tell on Jim. She therefore asserts that one ought not to tell on Jim. Of course, this is also what Mark assert. Consequently, in virtue of the parties' respective assertions, both express disapproval of telling on Jim. Given disagreement in expressed attitude, it thus seems that there is no disagreement. However, given that we know that they actually have the beliefs that they have, this seems wrong. Mary and Mark intuitively disagree. Second, suppose that Mary doesn't really think that one ought to tell on Jim, but that she merely wants to examine the issue. ${ }^{13}$ Mark, however, is not aware of this. Hence, in virtue of their assertions, Mary and Mark express approval and disapproval of telling on Jim respectively. If disagreement intuitions are supposed to be explained in terms of expressed attitudes, it seems that Mary and Mark disagree. However, given what we know about their respective beliefs, this seems wrong. Hence, the contextualist appeal to disagreement in expressed attitudes doesn't seem to work. It fails to adequately explain intuitive occurrences of disagreement in the right way. ${ }^{14}$

12 See e.g., Copp $(2001,2009)$ for arguments along these lines. One may also think that this brings about a too tight connection to attitudes (see e.g., Finlay 2004)

13 Suppose, for example, that Mary thinks that the only way of getting Mark to engage seriously with the question is by understanding her speech act as an assertion and that she thus manages to assert, albeit insincerely, that one ought not to tell on Jim. If you are inclined to think that Mary, even given her motive, fails to express the relevant attitude, simply assume that she mistakenly thinks that she has the belief in question.

14 It may be argued that the argument against the success of the contextualist explanation of disagreement intuitions in this paragraph trades on an ambiguity, i.e., whether the aim is to explain the intuitive disagreement between, on the one hand, the two parties or, on the other hand, between the assertions they make. Although a complete theory about 
In order to help diagnose the problems raised above, we should distinguish between at least two possible senses of disagreement, viz., disagreement in thought and disagreement in talk. ${ }^{15}$ On the one hand, there is a sense in which we intuit a conflict between two parties whose assertions express conflicting attitudes. On the other hand, there is a sense in which we intuit a conflict between two parties who simply have conflicting attitudes. Contextualists tend to focus on the former: they tend to be concerned with explaining disagreement in talk. However, as the two cases above illustrate, intuitions regarding disagreement in talk and disagreement in thought can come apart. Two persons can express conflicting attitudes despite not having conflicting attitudes (and vice versa). Moreover, even if both senses of disagreement deserve to be called senses of disagreement, the examples above also suggest that disagreement in thought is more fundamental. ${ }^{16} \mathrm{It}$ is perhaps plausible to think that the parties will intuit that they disagree in virtue of the expressed attitudes. However, it also seems plausible to think that they will, upon discovering that one party was self-deceived or for some other reason doesn't have the attitude he or she expresses, stop thinking of themselves as disagreeing. In other words, upon realizing that they don't have conflicting attitudes, they don't discover something that resolves their disagreement. Rather, what they discover is that they never really disagreed to begin with - although they thought they did because they thought that their respective assertions reflected their actual views. As Jackson and Pettit claims "the production of moral sentences makes public our disagreement; it does not create them" (Jackson and Pettit 1998: 251).

\section{Disagreement in attitude}

Disagreement in expressed attitudes went wrong because of its focus on the attitudes expressed rather than the attitudes actually had by the two parties. The latter idea is more in line with the standard Stevensonian or expressivist conception of disagreement: two parties disagree if they actually have conflicting attitudes. However, this idea also seems possible to combine

disagreement should explain both, it is the former that I have in mind and that I take to be a problem for the contextualist. The point is simply that judgments about disagreement in thought and talk (more on this distinction below) can come apart and that the latter therefore cannot fully explain the former. Of course, if the contextualist merely wanted to explain disagreement in assertion, then these objections can be disregarded. However, if this is the aim, I don't think much have been done to solve the disagreement problem for contextualism.

15 See, e.g., Egan (2014: 76). Similarly, Cappelen and Hawthorne (2009: 60-61) distinguish between disagreement as a state and disagreement as an activity. The latter sense requires that two parties are having a disagreement, i.e., that they are in some sense interacting, e.g., in an argument, discussion or the like. The former sense, by contrast, doesn't require that the disagreeing parties interact. Rather, it suffices that the parties have conflict beliefs.

16 See also MacFarlane (2014: 119-120) and Marques (2014) for similar views. 
with a contextualist theory. Consider, for example, the following idea pursed by Huvenes. ${ }^{17}$

The idea I am interested in is to view disagreement as a matter of the parties' having incompatible or conflicting attitudes. Two parties disagree just in case there is something towards which they have conflicting attitudes. (Huvenes 2012: 178-179; my emphasis)

Call this view Actual attitudinal disagreement.

Actual attitudinal disagreement: A disagrees with $B$ about $p$ in virtue of $\mathrm{A}$ and $\mathrm{B}$ having conflicting attitudes towards $\mathrm{p}$.

In fact, according to more traditional forms of contextualism, there is an intimate link between moral beliefs and attitudes. According to simple speaker relativism (aka subjectivism), to believe that one ought not to tell on Jim is to believe that one disapproves of not telling on Jim. One way of interpreting Dreier's contextualism (or indexical relativism as he calls it) is that the meaning of moral predicates is determined by the judge's moral standard where a moral standard is identical with (a set of) motivational attitudes. For example, to have a utilitarian standard is, roughly, to approve of maximizing happiness. Given such a moral standard, "Donating to charity is right," in the judge's idiolect, means that donating to charity maximizes happiness. These forms of contextualism explain why there is indeed a very close connection between moral beliefs and attitudes. This, in turn, may very well be one explanation of why it, to many parties, seems easy for a contextualist to make use of opposed attitudes to explain disagreement.

However, given a contextualist theory, it nevertheless seems conceivable to believe that Huck ought to tell on Jim without any concomitant approval of telling on Jim. As Huvenes writes, "a sincere utterance of [one ought to tell on Jim] is typically, though not invariably, accompanied by the speaker's having a certain attitude towards [telling on Jim]" (Huvenes 2011: 179 emphasis added). In other words, approval of telling on Jim is contingent. Consequently, if either (or both) party(ies) lacks the required attitude, the explanation of why they disagree disappears.

Nevertheless, given that Mary and Mark have their respective beliefs, there is still an appearance of disagreement. This takes us back to a point made in the beginning of this paper. By contrast, to the indexical example involving "It is hot here," where the appearance of disagreement disappears once we learn that the speakers are in different places, moral disagreement intuitions are much more robust. As long as the two parties' relevant moral beliefs are in place, we intuit that they disagree.

17 Huvenes focuses on predicates of taste, but I take it that the general idea can also be used in relation to moral predicates. 
It may be claimed that the moral disagreement intuitions aren't as robust as I claim them to be. Let me, therefore, quickly point to two different considerations that suggest that they are. First, if I discover that you are in a different place than I am, it clearly is infelicitous to signal disagreement by saying "No, it isn't hot here" or the like. By contrast, it always seems felicitous to signal disagreement with, e.g., Mary's moral judgment by saying "No, one ought not to tell on Jim" or the like. ${ }^{18}$ Second, there is empirical data that supports the modal robustness intuition. Justin Khoo and Joshua Knobe (2016), for example, advance considerations that purport to show that we don't necessarily intuit that at least one party of a moral dispute is wrong or mistaken. ${ }^{19}$ However, they nevertheless find evidence for thinking that disagreement intuitions don't go away. These two considerations suggest that moral disagreement intuitions are robust. Hence, in so far as we attribute Mary and Mark with the moral beliefs we have been toying with, it seems that people intuit that they disagree. The challenge is to make sense of this. ${ }^{20}$

One may think that this challenge is easily met by speaker relativism and/or the view attributed to Dreier above. This, however, isn't the case. According to speaker relativism, to believe that one ought to tell on Jim is to believe that one approves of telling on Jim. Although the accessibility to our own minds may perhaps be privileged, we are not infallible. Mary may believe falsely that she approves of telling on Jim whereas Mark believes (correctly) that he disapproves of telling on Jim, which is tantamount to Mark believing that one ought not to tell on Jim. Given the parties' respective beliefs, i.e.,

18 I may be argued that the use of disagreement markers merely matters to disagreement in talk. However, it seems that the use of disagreement markers is a way of signaling disagreement with the person. If Mary asserts that one ought to tell on Jim and Mark responds "No, one ought not to tell on Jim," then it seems plausible to think that Mark disagrees with Mary (or her belief) and not merely with her assertion. Rather, Mark takes Mary's assertion to be indicative of her belief on the matter, which is what he really disagrees with. Although the relation between disagreement in thought and talk is in need of a more thorough examination, it clearly seems that disagreement markers isn't merely relevant to disagreement in talk. Rather, most of the time, as Jackson and Pettit claim, disagreement in talk makes public disagreement in thought.

19 This constitutes an interesting challenge to both realists and quasi-realists, but this is an issue that we can set aside for the purpose of the present paper.

20 One may think that Khoo and Knobe's results are irrelevant in the present contexts since they haven't tested whether people's disagreement intuitions would be affected if we were to stipulate that the parties lacked the relevant attitudes. This is, of course, true. However, I very much doubt that people's intuitions would be affected by such a stipulation. On the one hand, insofar as we ascribe to, e.g., Mary and Mark, the moral beliefs we have been toying with, I predict that most people will intuit that they disagree. On the other hand, stipulating that the parties lack the relevant attitudes, may lead people to intuit that they don't disagree. However, I also hypothesize that this will be because this will interfere with ascribing to the parties the moral beliefs to begin with. Nevertheless, the main point about the Khoo and Knobe argument is that disagreement intuitions seem quite robust, but I grant that this intuition may be proved wrong. 
that Mary believes that one ought to tell on Jim and that Mark believes that one ought not to tell on Jim, we intuit that they disagree. However, since the parties don't have conflicting attitudes, the explanation of disagreement in terms of conflicting attitudes doesn't work. Again, the disagreement is lost.

A slightly different problem arises for the kind of view Dreier advances. Begin by considering how the content of a moral term is determined.

The content of a moral term is a function of the affective attitude of the speaker in the context. Thus, " $\mathrm{x}$ is good" means " $\mathrm{x}$ is highly evaluated by standards of system M," where $\mathrm{M}$ is filled in by looking at the affective or motivational states of the speaker and constructing from them a practical system. (Dreier 1990: 9)

Given that the meaning of "good" is a function of the affective attitude it may seem as if we will end up with a view according to which someone who believes that stealing is wrong will necessarily disagree in attitude with someone who believes that stealing is right. This, however, is not the case. Suppose Allan believes that stealing is wrong whereas Brenda believes that stealing is right. ${ }^{21}$ Suppose Allan's moral standard is a utilitarian one, i.e., he disapproves of not maximizing happiness. Brenda, by contrast, is of a more Kantian bent and approves of promoting autonomy. These two standards determine the meaning of "right" and "wrong" in their respective idiolects. Allan believes that stealing doesn't maximize happiness. Brenda believes that stealing promotes autonomy. These beliefs, of course, don't disagree. However, neither is disapproval of not maximizing happiness opposed to approval of promoting autonomy. Rather, in order for Allan and Brenda to disagree in attitude they must acquire more particularized attitudes, viz., disapproval of stealing and approval of stealing respectively. The problem is that the acquisition of these attitudes seems contingent. For example, either (or both) party(ies) may fail to acquire the particularized attitude due to some kind of irrationality or psychological failure, but without these attitudes we cannot explain the disagreement as a disagreement in (actual) attitude. ${ }^{22}$ Nevertheless, given that Allan believes that stealing is wrong and that Brenda believes that stealing is right, they intuitively disagree. However, since the parties don't have opposed attitudes, the intuition isn't accounted for. Disagreement is, again, lost. ${ }^{23}$

21 I will here omit certain complexities of Dreier's view, e.g., that the sometimes is filled in by looking at the motivational states of the larger community. We will return to this issue in section 7 .

22 See Eriksson 2015 for discussion on this matter in relation to certain forms of hybrid expressivist theories.

23 Similar considerations seem to be relevant to Finlay's definition "of fundamental disagreements as involving a basic conflict in preferred ends" (2014b: 234). Moreover, it is also not obvious that Dreier escapes the problem addressed above, i.e., if a person is mistaken about his or her standard, then it is conceivable that he or she will fail to have the corresponding attitude (the reason is because one forms one's moral judgment on basis of what one believes about one's moral standard). 


\section{Disagreement and practical commitments}

If the arguments above are right, contextualists run into problems regardless of whether they try to account for disagreement intuitions in terms of expressing conflicting attitudes or having conflicting attitudes since both accounts will fail to explain intuitive occurrences of disagreement. However, maybe the contextualist doesn't have to make sense of disagreement intuitions in terms of either having or expressing conflicting attitudes. Consider the following suggestion:

Even if strictly speaking our beliefs don't conflict with Huck's, in combination with subscription to conflicting standards these beliefs place us in conflict over the practical matter of what to do in situations like Huck's. In virtue of his subscription to standard Y, Huck's moral belief commits him to favor telling on fugitive slaves. In virtue of our subscription to standard Z, our moral belief commits us to oppose telling on fugitive slaves. Hence these noncontradictory moral beliefs precipitate a disagreement in attitude toward Huck's action. (Björnsson and Finlay 2010: 28)

This idea differs from the previous one advanced by Björnsson and Finlay. First, one can have the particular commitment to an attitude without giving voice to it. Hence, it differs from Disagreement in expressed attitude. Second, the idea doesn't require that the parties have the pertinent attitudes. Hence, it differs from the Disagreement in actual attitude. Rather, the idea seems to be the intuitive disagreement between two parties comes about via their respective commitments to (conflicting) attitudes. ${ }^{24}$ Given that the acquisition of the relevant attitudes is contingent, maybe this provides a solution the previous problems for contextualists. Call this conception Disagreement in attitudinal commitment.

Disagreement in attitudinal commitment: A and B disagree about $\mathrm{p}$ if their beliefs together with their moral standard commit them to opposed prescriptions or attitudes (regarding p). ${ }^{25}$

However, since this conception differs significantly the previous two suggestions, it also raises new questions. In particular, we need to examine

24 Confer Horwich (2010): “The conflict associated with contradictory beliefs consists in their potential, through inference, to engender conflicting desires and decisions. If I disagree with you about the truth of some empirical proposition, $\langle\mathrm{T}\rangle$, then that can easily result (via theoretical reasoning and given other premises) in our disagreeing about the truth of some more directly action-guiding belief, <If A is done then X will occur>. And if we both want $\mathrm{X}$ to occur then one of us will, on that account, be in favor of $\mathrm{A}$ being done, and the other won't" (Horwich 2010: 183).

25 Note also that this suggestion differs significantly from more standard conceptions of disagreement in attitude. 
how attitudinal commitments come about. We then need to examine whether it handles the problems with the previous accounts.

In order to examine how an attitudinal commitment comes about we must first ask what it is to endorse a certain standard. Björnsson and Finlay's idea seems to be the following: To endorse a standard is to have a preference for some end. To have a utilitarian standard, for example, is to have a preference that happiness is maximized. It is such a preference that fixes Huck's standard. Hence, for Mary to believe that one ought to tell on Jim is for Mary to believe that telling on Jim maximizes happiness. Although Björnsson and Finlay are not entirely clear on exactly how the attitudinal commitment comes about, it seems that the matter is one of simple instrumental rationality.

1. Mary believes that that one ought to tell on Jim

2. Mary has a preference for maximizing happiness.

3. Mary believes that telling on Jim maximizes happiness.

4. Based on 2 and 3, Mary is committed to favor (having a preference for) telling on Jim.

The idea is that Mary is committed to favor telling on Jim because telling on Jim is a means to her end - maximization of happiness - and it is irrational not to favor suitable means to one's ends. Mark's standard, by contrast, is fixed by a preference for some other end, e.g., a preference that agents are to be treated as ends rather than means. What Mark believes when he believes that one ought not to tell on Jim is thus that telling on Jim would be treating him as a means rather than as an end. Hence, the idea is that Mark is committed to having a preference in favor of not telling on Jim. Consequently, Mary and Mark are committed to conflicting attitudes.

Although this proposal is interesting, it also has problems. Plausibly, Mary's believing that telling on Jim is a means to maximizing happiness (i.e., her end), rationally commits her to telling on Jim, not to favor telling on Jim. This is most easily seen by considering the following possibility: although Mary believes that telling on Jim is a means to maximizing happiness, she may simultaneously believe that favoring (having a preference for) telling on Jim will not maximize happiness (because of the consequences of such an attitude). Hence, we can add $3^{*}$ to $1-4$ above:

1. Mary believes that one ought to tell on Jim.

2. Mary has a preference for maximizing happiness.

3. Mary believes that telling on Jim maximize happiness.

$3^{*}$. Mary believes that having a preference for telling on Jim will not maximize happiness.

$4^{\star}$. From 2 and $3^{\star}$, Mary is committed to not have a preference for telling on Jim. 
In this scenario, it seems that $4^{\star}$ is what we should conclude. In other words, it is rational for Mary to do that which is a means to her end, i.e., to tell on Jim and not to prefer to tell on Jim. Here we can toy with two variations. In one scenario, Mary is committed to no attitude in particular and in a second scenario she is committed to having a preference for not telling on Jim (depending on what we assume that she believes maximizes happiness). Regardless of which route we take, the problem of making sense of intuitive occurrences of disagreement will resurface. Despite thinking that one ought to tell on Jim, Mary is, because of her belief regarding the consequences of favoring of telling on Jim, committed to favoring not telling on Jim (in the latter scenario). This is the kind of attitude that Mark, who believes that one ought not to tell on Jim, is also committed to. Hence, despite the intuitive disagreement between the parties' respective moral beliefs, they are committed to the same attitude. Consequently, the account fails to explain disagreements where they intuitively occur (it will, for similar reasons, also fail to explain agreement where they intuitively occur). It may be objected that I have misunderstood how the attitudinal commitment comes about. Maybe this is true, but it nevertheless remains unclear whether there is some way of explicating this idea that avoids the problems raised above. ${ }^{26}$

\section{Disagreement and de dicto internalism}

The problem with the suggestions above is that they fail to explain how the moral belief, e.g., that one ought to tell on Jim, necessarily co-occurs in the right way with the right attitudes, i.e., approval of telling on Jim, which is supposed to account for the appearance of disagreement (in terms of disagreement in attitude). A way to try to get around this problem is to consider a move made by Jon Tresan $(2006,2009)$. Tresan has in different places argued in favor of de dicto internalism with a communal twist. According to this view, a moral belief may be a prosaically factual belief, but in order for the belief to count as a moral belief, it must be accompanied by the relevant pro- or conattitudes. Moreover, Tresan argues that moral beliefs need not be accompanied by attitudes at the individual level, but merely at the communal level. ${ }^{27}$ In fact, Dreier seems sympathetic to this communal feature. Sometimes the standard isn't filled in by the speaker's motivational attitudes, but "constructed from the attitudes of the larger community" (Dreier 1990: 25).

The nice feature, in this context, is that this move gets us a necessary connection between moral beliefs and attitudes. However, given the

26 Many thanks to Ragnar Francén for helping me think about these matters.

27 It should be noted that Tresan doesn't use de dicto internalism to make sense of moral disagreement, but to account for internalist intuitions. Moreover, Tresan is not a contextualist, but an invariantist. 
communal twist, we don't end up with the right result. It may be the case that the content of either party's moral belief is determined by attitudes of the community. If this is the case, then there will be (given contextualism) neither a disagreement in belief nor in attitude - since the judge doesn't have the pertinent attitude. An alternative is, of course, to drop the communal twist in favor of a strict individualistic de dicto internalism. On such a view, a moral belief may be a prosaically factual belief, but it counts as a moral belief only in so far as it is accompanied by a corresponding attitude at the individual level. For example, Mary's belief that one ought to tell on Jim is a moral belief if and only if Mary favors telling on Jim. Mark's belief that one ought not to tell on Jim, by contrast, counts as a moral belief if and only if Mark favors not telling on Jim. ${ }^{28}$ This move would seem to enable the contextualist to explain moral disagreement as a disagreement in attitude since a moral belief is guaranteed to be accompanied by a corresponding attitude. This, it seems, would help explain intuitive occurrences of moral disagreement in the right way and explain the modal robustness intuition. However, considering the de dicto move reveals a more general problem with the contextualist attempt to explain disagreement in term of disagreement in attitude. In order to bring out the problem, we need to note some of the important differences between expressivism and contextualism.

All the ideas considered above purport, in one way or other, to make sense of moral disagreement by taking over a key feature of expressivism, viz., that disagreement is to be understood in terms of conflicting attitudes. However, there are still important differences between the doctrines, two of which needs to be emphasized in the present context. The first difference concerns the nature of moral beliefs. According to expressivism, to believe that Huck ought to tell on Jim is to approve of telling on Jim. The attitude is, in other words, part of the moral belief itself. According to contextualism, by contrast, this is not the case. Rather, to believe that Huck ought to tell on Jim is to have a prosaically factual belief the value of which is contextually determined. The attitudinal part is, in other words, not part of the moral belief itself (this is the case even if one adheres the de dicto idea outlined in the previous paragraph). The second difference concerns the semantics. According to expressivism, we should explain the meaning of a sentence in terms of the attitude it expresses. Hence, the meaning of, e.g., "Huck ought to tell on Jim" should be understood in terms of the state of mind that the sentence functions to express, e.g., approval of Huck telling on Jim. According to contextualism, by contrast, this is not the case. The attitude is not part of the semantics of the sentence. Rather, the meaning of the sentence is exhausted

28 A question in relation to the de dicto idea is also what kind of attitude that a moral belief needs to be accompanied by. For example, suppose Jack is a utilitarian, believes that stealing fails to maximize happiness and therefore believes that stealing is wrong. Does his belief count as a moral belief only it is accompanied by disapproval of stealing or does it suffice that he disapproves of not maximizing happiness? 
by the proposition expressed. The attitudinal part is merely pragmatics. It is partly because of these differences that the connection between moral belief and attitude is contingent and risks failing to explain intuitive occurrences of disagreement in the right way. The de dicto idea avoids that problem. In order to see why this presents a problem for contextualist views, let us first consider the disagreement between Mary and Mark again.

(3) Huck ought to tell on Jim.

(4) Huck ought not tell on Jim.

Intuitively, Mary and Mark disagree in virtue of accepting these two respective moral beliefs and these two beliefs alone. In other words, moral disagreement intuitions are not merely modally robust, but the disagreement, i.e., the sense of conflict, is due to a conflict between the relevant moral beliefs.

In order to try to bring out this intuition more clearly, consider how we think about prosaically factual disagreement. Suppose John believes that Paris is the capital of France whereas Jane believes that Paris is not the capital of France. John and Jane clearly disagree. Such a disagreement is due to the fact that their respective beliefs cannot be true simultaneously. If there is no conflict between their respective beliefs, there is no disagreement regarding the capital of France. In this case, the disagreement is rather obviously located between the respective beliefs alone. Similarly, it seems intuitive to think that moral disagreements are due to two parties having either moral beliefs that cannot be true or false simultaneously or because they have moral beliefs that are constituted by attitudes that are in conflict. Below I will advance two further considerations in support of this.

First, consider someone whom you disagree with on a moral issue. In virtue of what do you, intuitively, disagree with that person? Presumably, you believe that that person has a moral belief that conflicts with your moral belief - not that that person has some other attitude or belief that conflicts with yours. For example, in order for the disagreement to be resolved, the person you disagree with will have to relinquish the moral belief in question. Second, consider the use of disagreement markers. For example, if Mary asserts that one ought to tell on Jim, I take this to express a moral belief that she endorses. You can express disagreement in a number of different ways, e.g., by saying "That's false," "You are mistaken" or "No, one ought not to tell on Jim." What is it, intuitively, that you think is false, mistaken or that you are somehow challenging by responding in this way? Again, it seems that the target of your disagreement is the moral belief Mary has or gives expression to. This seems to suggest that the disagreement intuitively is located between your respective moral beliefs. All in all, the considerations advanced above suggest that we intuit that two parties disagree because they have moral beliefs that are in conflict. 
If we want to explain the disagreement intuition in terms of disagreement in attitude, then the contextualist story seems to get things wrong. The reason is that the attitude is not part of the moral belief itself. For example, there is no conflict between Mary and Mark's moral beliefs. As Björnsson and Finlay write, "strictly speaking [their] beliefs don't conflict" (2010: 28). Rather, the disagreement intuition is supposed to be explained by something other than your moral beliefs. Consequently, the contextualist will fail to locate the disagreement in the right place. Again, when two people disagree on a moral issue, the disagreement seems to be due to some feature of their respective moral beliefs, but since the attitudinal part, according to contextualist views, isn't part of the moral belief itself, this intuition isn't accounted for. The de dicto view doesn't avoid this problem. Although it is true, given such a view, that a moral belief is always accompanied by the relevant pro- or con-attitude, the attitude is not part of the moral belief itself, which is what we intuitively disagree with. Consequently, contextualism (in any guise) will fail to make sense of the intuitive location of the disagreement, i.e., that the disagreement is due to the parties having conflicting moral beliefs. Expressivists, by contrast, think that moral beliefs are constituted by the relevant attitudes that are in conflict and thus locate the disagreement in the intuitively right place, i.e., as a disagreement between the two parties' moral beliefs.

The contextualist could, of course, argue that there is some way to explain these intuitions away or provide an error-theory regarding the location intuition. ${ }^{29}$ However, until this has been satisfactorily done, we have reason to think that the attitude is part of the moral judgment - assuming that we think that moral disagreement is best accounted for in terms of conflicting attitudes. Moreover, and more generally, this also shows that the contextualist cannot simply take over the standard expressivist explanation. Rather, explaining disagreement intuitions using the disagreement in attitude idea requires much more work if it is to fly within a contextualist framework.

\section{Concluding remarks}

A standard objection to moral contextualism is that such a thesis cannot make sense of moral disagreement. This paper has considered a popular suggestion advanced in the literature, viz., that contextualists simply can adopt the standard expressivist story. We should not think of the disagreement between two parties as a disagreement in belief, but as a disagreement in attitude - thus mimicking the expressivist idea that there can be moral disagreements without disagreement in belief. This paper has argued that this is easier said than done. In fact, if the arguments of this paper are right, we have reason to be skeptical about its success. This paper has examined

29 For example, upon being told that the disagreement is due to the necessarily accompanying attitude, I still intuit that our moral beliefs are in conflict. Either this is due to some error on my part or the error is locating the disagreement in the wrong place. 
a number of different ways in which disagreement in attitude can be incorporated into a contextualist framework all of which lead to problem: the purported explanations of disagreement fail to adequately explain intuitive occurrences of disagreement, the robustness of disagreement intuitions and/ or locate the disagreement in the intuitively right place.

Of course, there are other ways of trying to account for disagreement intuitions (see footnote 8) within a contextualist framework. Moreover, one may think that the standard expressivist account is seriously flawed (Ridge $2013,2014)$ and think that there are better alternatives. However, the purpose of this paper is merely to examine contextualism in conjunction with the standard expressivist account, i.e., disagreement in attitude. Examining other alternatives is outside the scope of this paper. Nevertheless, those of us who think that disagreement in attitude is a plausible account of disagreement (even if it requires some tinkering) and who think that certain domains are characterized by being intimately connected to nondoxastic attitudes, e.g., ethics and taste, still have reason to think that expressivism is superior to rival theories. If this is right, arguments from disagreement may still have, at least some, semantic significance and thus push us in the direction of expressivism.

\section{References}

Ayer, A. J. (1936). Language, Truth and Logic, $2^{\text {nd }}$ Edition, London: Victor Gollancz Ltd.

Barker, C. (2002). “The dynamics of vagueness." Linguistics and Philosophy 25(1): $1-36$.

Björnsson, G. and Finlay, S. (2010). "Metaethical contextualism defended." Ethics 121: 7-36.

Blackburn, S. (1984). Spreading the Word: Groundings in the Philosophy of Language, Oxford: Oxford University Press.

Blackburn, S. (1991). "Just Causes." Philosophical Studies, 61: 3-17.

Copp, D. (2001). "Realist-expressivism: A neglected option for moral realism," Social Philosophy and Policy 18: 1-43.

Copp. D. (2009). "Realist-Expressivism and Conventional Implicature" in Oxford Studies in Metaethics Vol. 4, ed. R. Shafer-Landau: 167-202. Oxford: Oxford University Press.

Dreier, J. (1990). “Internalism and Speaker Relativism.” Ethics 101(1): 6-26.

Dreier, J. (1999). “Transforming Expressivism.” Noûs 33(4): 558-72.

Dreier, J. (2009). "Relativism (and Expressivism) and the Problem of Disagreement." Philosophical Perspectives 23: 79-110. 
Egan, A. (2010). "Disputing about taste" in Disagreement, Richard Feldman and Ted A. Warfield (eds), Oxford: Oxford University Press.

Egan, A. (2014). "There's something funny about comedy: A case study in faultless Disagreement." Erkenntnits 79: 73-100.

Eriksson, J. (2015). "Explaining disagreement: a problem for hybrid expressivists." Pacific Philosophical Quarterly 96(1): 39-53.

Eriksson, J. (2016). "Attitudinal complexity and two senses of disagreement in attitude." Erkenntnis 81(4): 775-794.

Finlay, S. (2004). "The conversational practicality of value judgments." The Journal of Ethics 8: 205-223.

Finlay, S. (2014a). Confusion of Tongues: A Theory of Normative Language. Oxford: Oxford University Press.

Finlay, S. (2014b). "The pragmatics of Normative Disagreement," in Having it both ways, Guy Fletcher and Michael Ridge (eds), Oxford: Oxford University Press: 124-148.

Gibbard, A. (1990). Wise Choices, Apt Feelings. Oxford: Clarendon Press.

Gibbard, A. 2003. Thinking How to Live, Cambridge, Mass.: Harvard University Press.

Hare, R. M. (1952). The Language of Morals. Oxford: Clarendon Press.

Harman, G. (1996). "Moral Relativism" in Moral Relativism and Moral Objectivity, Gilbert Harman and Judith Jarvis Thomson, Cambridge, Mass., Blackwell.

Horgan, T. and M. Timmons (1991). "New-Wave Moral Realism meets Moral Twin Earth" in John Heil (ed.), Rationality, Morality, and Self-Interest. Lanman Md: Rowman and Littlefield, pp. 115-33.

Horwich, P. (2010). Truth-meaning-reality. Oxford: Clarendon Press.

Huvenes, T. (2012). "Varieties of Disagreement and Predicates of taste." Australasian Journal of Philosophy 90(1): 167-181.

Khoo, J. and Knobe, J. (2016). "Moral Disagreement and Moral Semantics" Noûs 50(2): 1-35.

Köhler, S. (2012). "Expressivism, subjectivism and moral disagreement," Thought 1: 71-78.

López de Sa, D. (2009). "Presuppositions of commonality: An indexical relativist account of disagreement" in Garcia-Carpintero, M. and Kölbel, M. (eds.) Relative Truth, Oxford: Oxford University Press.

Jackson, F (2008). "The argument from the persistence of moral disagreement" in Oxford Studies in Metaethics $3^{\text {rd }}$ ed, Russ Shafer-Landau (ed.) Oxford: Oxford University Press. 
Jackson, F and Pettit, P (1998). “A Problem for Expressivism.” Analysis 58(4): 239-51.

MacFarlane, J. (2014). Assessment Sensitivity: Relative Truth and Its Applications. Oxford: Oxford University Press.

Marques, T. (2014). Doxastic Disagreement." Erkenntnis 79: 121-142.

Marques, T. \& García-Carpintero, M. (2014). "Disagreement about taste: commonality presuppositions and coordination." Australasian Journal of Philosophy.

Plunkett, D and Sundell, T. (2013). "Disagreement and the Semantics of Normative and Evaluative Terms." Philosophers' Imprint 13: 1-37.

Recanati, F. (2007). Perspectival Thought. Oxford: Oxford University Press.

Ridge, M. (2013). “Disagreement.” Philosophy and Phenomenological Research 86: 41-63.

Ridge, M. (2014). Impassioned Belief. Oxford: Oxford University Press.

Stevenson, C. (1944). Ethics and Language. New Haven. Yale University Press.

Stevenson, C. (1962). Facts and Values. New Haven. Yale University Press.

Sundell, T. (2011). “Disagreements about taste.” Philosophical Studies 155: 267-288.

Tersman, F. (2006). Moral Disagreement. Cambridge: Cambridge University Press.

Tresan, J. (2006). "De Dicto internalist cognitivism." Noûs 40(1): 143-65.

Tresan, J. (2009). "The challenge of communal internalism." The Journal of Value Inquiry 43: 179-99

Wong, D. (1984). Moral Relativity. Berkeley: University of California Press. 